Anyone planning a talk to either adult or school groups should obtain a copy for reference purposes. The interesting material developed in presenting this paper will provide some of the most useful arguments in putting across the topic. A full bibliography is also provided to round out the subject.

\title{
A CORRECTION TO YOUR 1952 SUPPLEMENT
}

For the past year J. E. Bier was the Regional representative for Ontario on the Sub-Committee on Forest Pathology, not L. T. White, as listed in the Report of the Standing Committee on Forest Entomology and Forest Pathology for the year ending March 31, 1951. Furthermore, the list of the members of the Sub-Committee on Forest Pathology which appeared in the March, 1952 supplement, should be revised as follows:
J. E. Bier
F. S. McKinnon
H. W. Eades
H. J. Hodgins
J. S. Mottishaw
A. W. McCallum
V. J. Nordin
R. E. Foster
L. T. White, Chairman
R. Pomerleau
C. G. Riley
J. T. Basham, Secretary

\section{POSITIONS WANTED 1}

FORESTER-20 years' experience in logging, road making, cruising, fire protection, some forest research, desires work in office where his bush experience might be used. Has office experience in mapping, cost estimates, and cost recapping.-Code Number O-1.

Forester-University of Toronto 1944 - 1 year Division of Timber Management, Ontario Government. 4 Years on Pulp operations-1 Year Control Man-2 Years Asst. District Logging Superintendent1 Year as Asst. Divisional Forester. Experience covers cruising, cutting, hauling, camp and road construction, preparation of working plans, and forest inventories. Desires position in any of the following fields: Control, Forestry, Operating. F-1.

1 Please reply to G. A. Sinclair, Laboratory of Forest Pathology, 144 Front St., Weot, Toronto, Ontario, using the indicated code number. 